\title{
A comprehensive study of different types of speck impurities present in bleached eucalypt kraft pulps using PY-GC/MS
}

\author{
José C. del Río ${ }^{\mathrm{a}, *}$, Marina Hernando ${ }^{\mathrm{b}}$, Pedro Landín ${ }^{\mathrm{b}}$, \\ Ana Gutiérrez ${ }^{\mathrm{a}}$, Javier Romero ${ }^{\mathrm{b}}$ \\ ${ }^{\text {a }}$ Instituto de Recursos Naturales y Agrobiología de Sevilla, P.O. Box 1052, 41080 Seville, Spain \\ ${ }^{\mathrm{b}}$ ENCE, Centro de Investigación y Tecnología, Ctra Campañó, Ribeiro-Vao, 36157 Pontevedra, Spain
}

Received 18 October 2002; received in revised form 6 December 2002; accepted 20 February 2003

\begin{abstract}
Analytical pyrolysis in combination with gas chromatography and mass spectrometry (PyGC/MS) has been used to characterize a wide set of different speck impurities occurring in total chlorine-free (TCF) kraft pulps made from eucalypt (Eucalyptus globulus) wood. The specks included pitch, rubber and plastic impurities and were previously classified by mill technicians upon visual checking. Samples of eucalypt wood chloroform extracts, TCF bleached pulps, as well as a large series of rubber and plastic items taken from different parts of the machinery were also selected for this study. The Py-GC/MS evaluation showed that, except for the impurities classified as plastics, the differentiation made between rubber and pitch by visual checking may give erroneous results. Apart from the presence or absence of wood extractives in some samples, most of the impurities analyzed in this work, even those that were unambiguously classified as pitch by mill technicians upon visual checking, showed to contain synthetic rubbers. Finally, the pyrograms of the specks and those of reference rubbers were used as fingerprints to trace the source of contamination.
\end{abstract}

(C) 2003 Elsevier Science B.V. All rights reserved.

Keywords: Pulp; Impurities; Specks; Pitch; Rubber; Plastics; Pyrolysis

* Corresponding author. Tel.: +34-95-462-4711; fax: +34-95-462-4002.

E-mail address: delrio@irnase.csic.es (J.C. del Río). 


\section{Introduction}

The presence of impurities in paper pulp can severely impair product quality and is responsible for important economic losses in the pulp industry. The origin of the impurities is mainly due to wood extractives, which are difficult to remove during pulping and bleaching, and may deposit alone or with other components such as inorganic salts, fibers, and defoamers and cause sticky deposits (the so-called pitch) on process equipment and in pulp products [1,2]. On the other hand, synthetic polymers, such as rubbers and plastics, arising from machine breakage in different parts of the pulp mills can also be found in the pulp [3-7]. Most of the rubber and plastic fragments accumulate in the filters along the process and can be thus eliminated, however, if the particles are small enough to pass the cleaners, they may accumulate in the pulp as impurities. The rubber items usually found are polyisoprene, polystyrene, poly- $\alpha$-methylstyrene and polybutadiene while plastics made up of polyethylene, polypropylene and polyamide can also be found as impurities in pulp.

A gross differentiation of the impurities present in pulp into pitch, rubber and plastics is routinely performed at pulp mills by visual checking of their physical aspects. However, although plastics are easily differentiated from other impurities, this is not the case between pitch and rubber. This differentiation is highly inaccurate and may lead to misinterpretations as some types of rubber could be confused with pitch. A rapid and accurate characterization and differentiation of the impurities present in pulp are necessary so that appropriate measures or treatments can be undertaken.

Analytical pyrolysis coupled with gas chromatography and mass spectrometry (Py-GC/MS) enables a rapid characterization of very small amounts of material and is therefore ideally suited to characterize impurities in pulp and hence to distinguish between pitch and different synthetic polymers. Several papers have successfully used Py-GC/MS for the identification of commonly found impurities in pulp and paper matrices [3-8]. In this work, Py-GC/MS has been used to analyze a wide series of speck impurities collected from eucalypt total chlorine-free (TCF)-bleached kraft pulp. On the other hand, wood extractives, cellulose fibers and a large series of reference rubber items from different parts of the pulp mill were also analyzed in order to establish the source of the impurities.

\section{Material and methods}

\subsection{Description of the samples}

A total of 56 specks were collected from TCF-bleached kraft pulp made of eucalypt (Eucalyptus globulus) wood. The bleaching sequence was OQPoP (prebleaching with oxygen, a quelating stage and two hydrogen peroxide stages, one of them under oxygen pressure) and the final TCF pulp had a kappa number 4 . The collected impurities were classified by mill technicians according to their usual 
procedure upon visual checking into different categories, namely "flexible rubbers", "perished rubbers", "green rubbers", "possible rubbers", "possible pitch", "pitch", and "plastics". At the same time, several pieces of rubber items arising from different parts of the mill were collected and subsequently cooked and bleached before analysis by Py-GC/MS and their pyrograms were used as fingerprints. On the other hand, E. globulus wood chloroform extracts (which were extracted in a Soxhlet apparatus with acetone and then the acetone extracts were evaporated to dryness, redissolved in chloroform, and evaporated again to dryness before the analysis by PyGC/MS) and TCF-bleached pulp from Pontevedra pulp mill were also analyzed by Py-GC/MS. All impurities were picked and separated from cellulose fibers with tweezers in a microscope, placed in special quartz tubes, and analyzed by automatic Py-GC/MS without any other treatment.

\subsection{Pyrolysis-gas chromatography/mass spectrometry}

Analytical pyrolysis was performed using a CDS Pyroprobe AS-2500 Autosampler. The AS-2500 provides hand-free analysis of up to 36 samples. The sample was placed in a quartz tube of $2 \mathrm{~mm} \times 40 \mathrm{~mm}$ and put into the sample tray. The pyrolysis was carried out at $610{ }^{\circ} \mathrm{C}$ for $10 \mathrm{~s}$. The pyrolysis chamber was kept at $265^{\circ} \mathrm{C}$ and purged with helium in order to transfer the pyrolysis products as quickly as possible to GC column. The pyrolyser was connected to an Agilent 6890 gas chromatograph equipped with an on-column injector and a fused silica capillary column (DB5 MS, $30 \mathrm{~m} \times 0.25 \mathrm{~mm}$ ID, $0.25 \mu \mathrm{m}$ film thickness) coupled to an Agilent $5973 \mathrm{~N}$ mass spectrometer. The chromatograph was programmed from $40{ }^{\circ} \mathrm{C}(1 \mathrm{~min})$ to $300{ }^{\circ} \mathrm{C}$ at a rate of $6{ }^{\circ} \mathrm{C} \mathrm{min}{ }^{-1}$. The final temperature was held for $20 \mathrm{~min}$. The injector was programmed from 47 to $300{ }^{\circ} \mathrm{C}$ at $200{ }^{\circ} \mathrm{C} \mathrm{min}{ }^{-1}$, while GC/MS interface was kept at $300{ }^{\circ} \mathrm{C}$. The compounds were identified by comparing the mass spectra thus obtained with those of Wiley computer libraries, and by mass fragmentography.

\section{Results and discussion}

\subsection{Pyrolysis of reference materials}

Prior to the analysis of the speck impurities, a series of reference materials, such as E. globulus wood chloroform extracts, a TCF-bleached pulp and a wide set of rubber items arising from different parts of the mill were analyzed by Py-GC/MS.

\subsubsection{Pyrolysis of E. globulus wood chloroform extracts}

As one of the possible sources of the speck impurities in pulp could be deposits of lipophilic wood extractives (pitch), a sample of E. globulus wood was extracted and analyzed by Py-GC/MS. The pyrogram of the chloroform extracts is shown in Fig. 1 and the identities of the lipophilic compounds released are given in Table 1. Fatty acids, including tetradecanoic, hexadecanoic, 9,12-octadecadienoic, 9-octadecenoic, octadecanoic and eicosanoic acids, as well as squalene and several steroid 


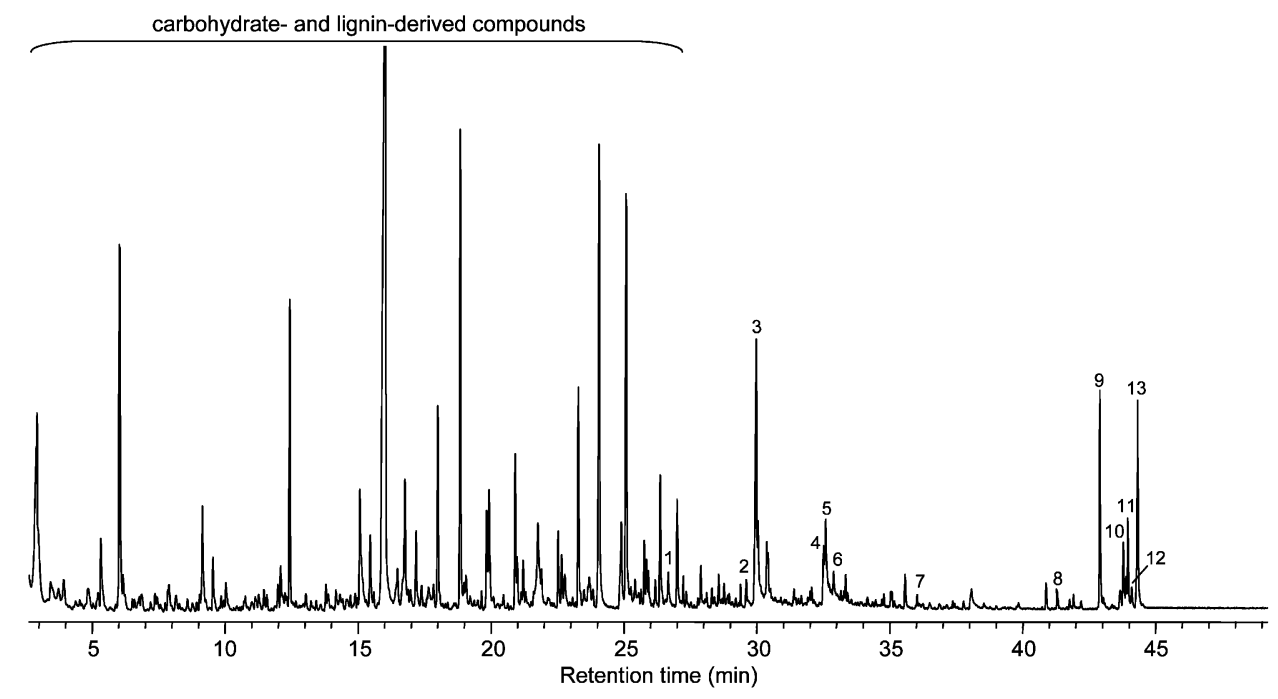

Fig. 1. Py-GC/MS analysis of the chloroform extracts of E. globulus wood. For peak identity, see Table 1.

Table 1

Main lipophilic compounds identified in the analysis of chloroform extracts of E. globulus wood by PyGC/MS

\begin{tabular}{rll}
\hline No. & Compounds & MS fragments $(\mathrm{m} / z)$ \\
\hline 1 & $n$-Tetradecanoic acid & $60 / 73 / 129 / 185 / 228$ \\
2 & 9 -Hexadecenoic acid & $55 / 69 / 83 / 97 / 236 / 254$ \\
3 & $n$-Hexadecanoic acid & $60 / 73 / 129 / 256$ \\
4 & 9,12 -Octadecadienoic acid & $55 / 67 / 81 / 95 / 280$ \\
5 & 9 -Octadecenoic acid & $55 / 67 / 81 / 97 / 264 / 282$ \\
6 & $n$-Octadecanoic acid & $60 / 73 / 129 / 284$ \\
7 & $n$-Eicosanoic acid & $60 / 73 / 129 / 312$ \\
8 & Squalene & $69 / 81 / 95 / 137 / 410$ \\
9 & Steroid hydrocarbon $\mathrm{C}_{29: 2}$ & $145 / 213 / 255 / 275 / 381 / 396$ \\
10 & Steroid hydrocarbon $\mathrm{C}_{29: 1}$ & $147 / 215 / 257 / 383 / 398$ \\
11 & Steroid hydrocarbon $\mathrm{C}_{29: 2}$ & $145 / 255 / 381 / 396$ \\
12 & Steroid hydrocarbon $\mathrm{C}_{29: 3}$ & $135 / 143 / 394$ \\
13 & Steroid hydrocarbon $\mathrm{C}_{29: 2}$ & $145 / 147 / 213 / 275 / 381 / 396$ \\
\hline
\end{tabular}

hydrocarbons with a $\mathrm{C}_{29}$ skeleton, were among the lipophilic compounds released upon Py-GC/MS [9]. Sitosterol and sitosterol esters, which are also important lipophilic compounds from eucalypt wood responsible for pitch deposition during pulp manufacturing [3,10-13], are out of Py-GC/MS analytical window because of their high molecular weight. Therefore, in this work, we focussed only on the lipophilic compounds that are released upon Py-GC/MS and observed in the analytical conditions used here in order to confirm the presence of deposits of wood 
extractives (pitch) in the speck impurities. It should be noted here that TCF bleaching with hydrogen peroxide has a minor influence on the composition of wood extractives [12]. Therefore, the composition of the lipophilic extractives in the eucalypt TCF kraft pulp is very similar to that of E. globulus extractives, except for the triglycerides that are hydrolyzed during cooking [12]. Other compounds released from the chloroform extracts were lignin-derived phenols with guaiacyl and syringyl structures and compounds arising from carbohydrates such as furfural, furfurylalcohol and levoglucosan.

\subsubsection{Pyrolysis of eucalypt TCF kraft pulp}

Since in some cases it was difficult to completely separate the impurities from the cellulose fiber, it was necessary to pyrolyze TCF pulp in order to distinguish the compounds arising from the pyrolysis of the pulp from those arising from the impurities. The pyrogram of a TCF pulp is shown in Fig. 2 and the identities of the released compounds are listed in Table 2 . The main compounds identified were hydroxypropanone, furfural, several furanones and levoglucosan. The content of wood extractives in the pulp was very low $(0.07 \%)$ and therefore they could not be detected upon Py-GC/MS.

\subsubsection{Pyrolysis of selected rubber items from different parts of the pulp mill}

A series of 19 reference rubber items (R01-R19) were collected at different locations along the pulp mill. Details on their location are given in Table 3. These samples were analyzed by Py-GC/MS after being cooked and bleached in a similar manner as TFC pulp. Table 4 summarizes the results obtained in this study (only characteristic compounds were considered). The different rubber items collected were basically composed of polyisoprene, polystyrene, poly- $\alpha$-methylstyrene, poly-

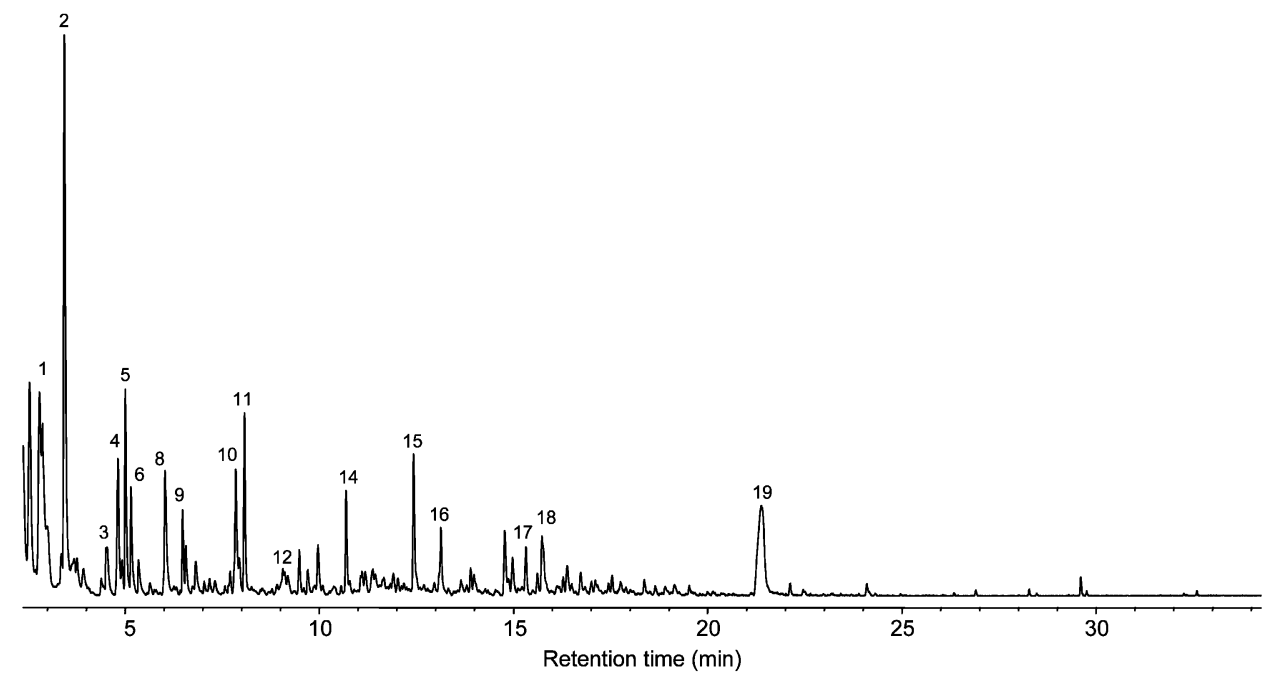

Fig. 2. Py-GC/MS of a TCF pulp sample. For peak identity, see Table 2. 
Table 2

Main compounds released after pyrolysis of TCF eucalypt kraft pulp

\begin{tabular}{rll}
\hline No. & Compounds & MS fragments $(\mathrm{m} / z)$ \\
\hline 1 & Hydroxyacetaldehyde & $42 / 56 / 58 / 60$ \\
2 & Hydroxypropanone & $43 / 74$ \\
3 & (3H) Furan-2-one & $55 / 84$ \\
4 & 3-Hydroxypropanal & $43 / 57 / 73 / 74$ \\
5 & Butanedial & $43 / 57 / 58$ \\
6 & Methylpyruvate & $43 / 102$ \\
7 & (2H) Furan-3-one & $54 / 84$ \\
8 & Furfural & $95 / 96$ \\
9 & Furfuryl alcohol & $53 / 69 / 81 / 97 / 98$ \\
10 & (5H) Furan-2-one & $55 / 84$ \\
11 & Hydroxycyclopentenone & $42 / 55 / 69 / 98$ \\
12 & Methylfurfural & $53 / 81 / 109 / 110$ \\
13 & 4-Hydroxy-5,6-dihydro(2H)pyran-2-one & $58 / 114$ \\
14 & 2-Hydroxy-3-methyl-2-cyclopenten-1-one & $55 / 69 / 83 / 97 / 112$ \\
15 & 2,3-Dihydro-5-methylfuran-2-one & $44 / 57$ \\
16 & Dihydrohydroxypyran-1-one & $56 / 84 / 114$ \\
17 & Dianhydro- $\alpha$-D-glucopyranose & $57 / 69 / 85 / 98 / 114 / 144$ \\
18 & Hydroxymethylfurfural & $69 / 97 / 126$ \\
19 & Levoglucosan & $60 / 73 / 98 / 144$ \\
\hline
\end{tabular}

Table 3

List of reference rubbers collected at different locations at ENCE pulp mill in Pontevedra, Spain

\begin{tabular}{ll}
\hline Reference rubbers & Location at the mill \\
\hline R01 & Insulation from drying machine ventilation shaff \\
R02 & Baffle seal \\
R03 & Chipper belt conveyor \\
R04 & From drying machine No. 2 press support platform \\
R05 & Andritz filter compartment seal \\
R06 & Upper seal on C350 pulp centricleaner \\
R07 & Chip feed belt conveyor \\
R08 & Digester feed belt conveyor \\
R09 & Lower seal O20 (perished rubber) \\
R10 & Press rubber No. 2 catwalk \\
R11 & No. 1 B11 seal (perished rubber) \\
R12 & Flexible motor coupling \\
R13 & Soft miner sheathing on electric cables \\
R14 & Hard outside sheathing on electric cables \\
R15 & B70 fiber-box seal \\
R16 & Twin Nip press safety box \\
R17 & B11/O20 lower door seal \\
R18 & Digester box conveyor belt \\
R19 & L80 filter seal No. 1 \\
&
\end{tabular}


Table 4

Relative abundance (percent of total peak area in the pyrogram) of characteristic compounds obtained in the analysis by Py-GC/MS of reference rubbers collected at different locations at ENCE pulp mill in Pontevedra, Spain

\begin{tabular}{|c|c|c|c|c|c|c|c|c|c|c|c|c|c|c|c|c|c|c|c|}
\hline Compounds & R01 & R02 & R03 & R04 & R05 & R06 & R07 & R08 & R09 & $\mathrm{R} 10$ & $\mathrm{R} 11$ & $\mathrm{R} 12$ & $\mathrm{R} 13$ & R14 & $\mathrm{R} 15$ & $\mathrm{R} 16$ & $\mathrm{R} 17$ & $\mathrm{R} 18$ & R19 \\
\hline Butadiene & n.d. & 8 & 6 & 2 & n.d. & n.d. & 6 & 11 & 3 & 2 & 8 & n.d. & n.d. & n.d. & n.d. & tr. & n.d. & 8 & 9 \\
\hline Toluene & 7 & 8 & 8 & 2 & n.d. & 1 & 7 & 7 & 11 & 4 & 1 & 5 & 5 & 4 & n.d. & 7 & 7 & 8 & 1 \\
\hline 4-Vinylcyclohexene & 5 & 7 & 7 & 2 & n.d. & n.d. & 6 & 7 & 5 & 2 & 2 & n.d. & n.d. & n.d. & n.d. & 2 & 2 & 7 & 2 \\
\hline Isoprene & $\operatorname{tr}$ & tr. & 2 & 23 & n.d. & n.d. & 9 & 7 & $\operatorname{tr}$. & 23 & 10 & n.d. & n.d. & n.d. & n.d. & 26 & 16 & 6 & 17 \\
\hline Isoprene dimers & n.d. & n.d. & 2 & 37 & n.d. & n.d. & 12 & 5 & n.d. & 36 & n.d. & n.d. & n.d. & n.d. & n.d. & 34 & 38 & 5 & n.d. \\
\hline Isoprene trimers/tetramers & n.d. & n.d. & n.d. & 4 & n.d. & n.d. & $\operatorname{tr}$. & n.d. & n.d. & 4 & n.d. & n.d. & n.d. & n.d. & n.d. & 5 & 10 & n.d. & n.d. \\
\hline Styrene & 4 & 29 & 21 & 3 & n.d. & 1 & 30 & 34 & 36 & 4 & 1 & 4 & 4 & 4 & n.d. & 7 & 1 & 29 & 1 \\
\hline$\alpha$-Methylstyrene & n.d. & 7 & 7 & 20 & n.d. & n.d. & 6 & 5 & 7 & 19 & 1 & n.d. & n.d. & n.d. & n.d. & 3 & n.d. & 5 & tr. \\
\hline Diphenylpropane & n.d. & 2 & 2 & n.d. & n.d. & n.d. & 2 & 1 & 2 & n.d. & n.d. & tr. & n.d. & n.d. & n.d. & 1 & n.d. & 2 & n.d. \\
\hline Indene & 4 & 1 & tr. & tr. & n.d. & n.d. & $\operatorname{tr}$. & tr. & tr. & tr. & 20 & 1 & 2 & 1 & n.d. & 1 & n.d. & $\operatorname{tr}$ & 24 \\
\hline Indene derivatives & 9 & 2 & 4 & n.d. & n.d. & n.d. & n.d. & 2 & 3 & n.d. & 3 & 1 & 2 & 2 & n.d. & 1 & tr. & 2 & 5 \\
\hline Naphthalene and derivatives & 8 & 2 & 2 & tr. & n.d. & n.d. & 1 & $\operatorname{tr}$ & 2 & n.d. & n.d. & 2 & 7 & 5 & n.d. & n.d. & n.d. & 2 & n.d. \\
\hline Phthalates & 25 & 6 & 6 & 1 & 48 & 79 & n.d. & 1 & 3 & 1 & 25 & 32 & 40 & 34 & 74 & 3 & 5 & 4 & 1 \\
\hline Dibutylsebacate & n.d. & n.d. & n.d. & n.d. & 16 & n.d. & n.d. & n.d. & n.d. & n.d. & n.d. & n.d. & n.d. & n.d. & n.d. & n.d. & n.d. & n.d. & n.d. \\
\hline N-compounds & n.d. & 2 & 2 & $\operatorname{tr}$. & n.d. & n.d. & 2 & 1 & n.d. & n.d. & 13 & n.d. & n.d. & n.d. & n.d. & n.d. & tr. & 2 & 15 \\
\hline Fluorine compounds & n.d. & n.d. & n.d. & n.d. & 28 & 18 & n.d. & n.d. & n.d. & n.d. & n.d. & n.d. & n.d. & n.d. & 24 & n.d. & n.d. & n.d. & n.d. \\
\hline Total diagnostic compounds ${ }^{\mathrm{a}}$ & 62 & 74 & 68 & 94 & 92 & 99 & 81 & 80 & 72 & 95 & 84 & 45 & 60 & 50 & 98 & 90 & 79 & 80 & 75 \\
\hline
\end{tabular}

tr., trace amounts; n.d., not detected; all rubbers were cooked and bleached in the same manner as TCF pulp.

a The rest corresponded to non-diagnostic compounds such as other alkylbenzenes. 
butadiene and fluororubber (viton). The pyrograms of these reference rubbers were used as characteristic fingerprints for the identification of the rubber impurities that appear in pulps in order to trace their source from different parts of the machinery.

\subsection{Characterization of speck impurities occurring in chlorine-free pulp}

A wide set (56 samples) of speck impurities found in chlorine-free pulps were collected and analyzed by Py-GC/MS. Attending to their physical aspects, they were previously classified by mill technicians upon visual checking into different categories, namely rubbers ("flexible rubbers", "perished rubbers", "green rubbers", "possible rubbers"), pitch ("possible pitch", "pitch") and plastics ("plastics"). However, this differentiation is highly inaccurate and a detailed characterization of the chemical composition of the impurities among the different categories is needed. For that purpose, Py-GC/MS was used. Figs. 3-6 show some examples of representative pyrograms of the studied impurities. The list of the main compounds identified is in Table 5 .

\subsubsection{Py-GClMS of impurities classified as rubbers ("flexible rubbers", "perished} rubbers", "green rubbers" and "possible rubbers")

The Py-GC/MS analysis of all these samples, which were classified as rubber impurities by mill technicians, corroborated that all they contained rubbers. However, different types of synthetic polymers were identified and their origin could be easily traced by comparison with the reference materials already analyzed. The Py-GC/MS results are summarized in Table 6, where only the most representative and characteristic compounds have been considered.

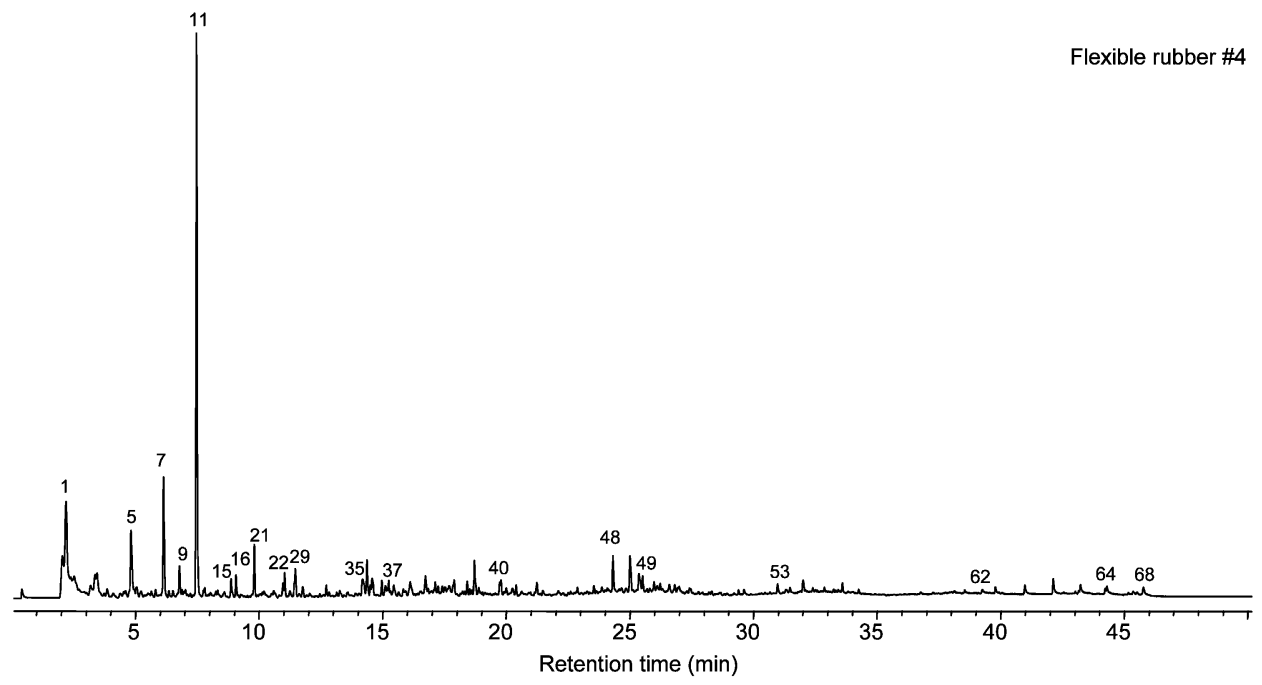

Fig. 3. Py-GC/MS of a selected impurity in TCF pulp classified as "flexible rubber" (4). For peak identities, see Table 5. 


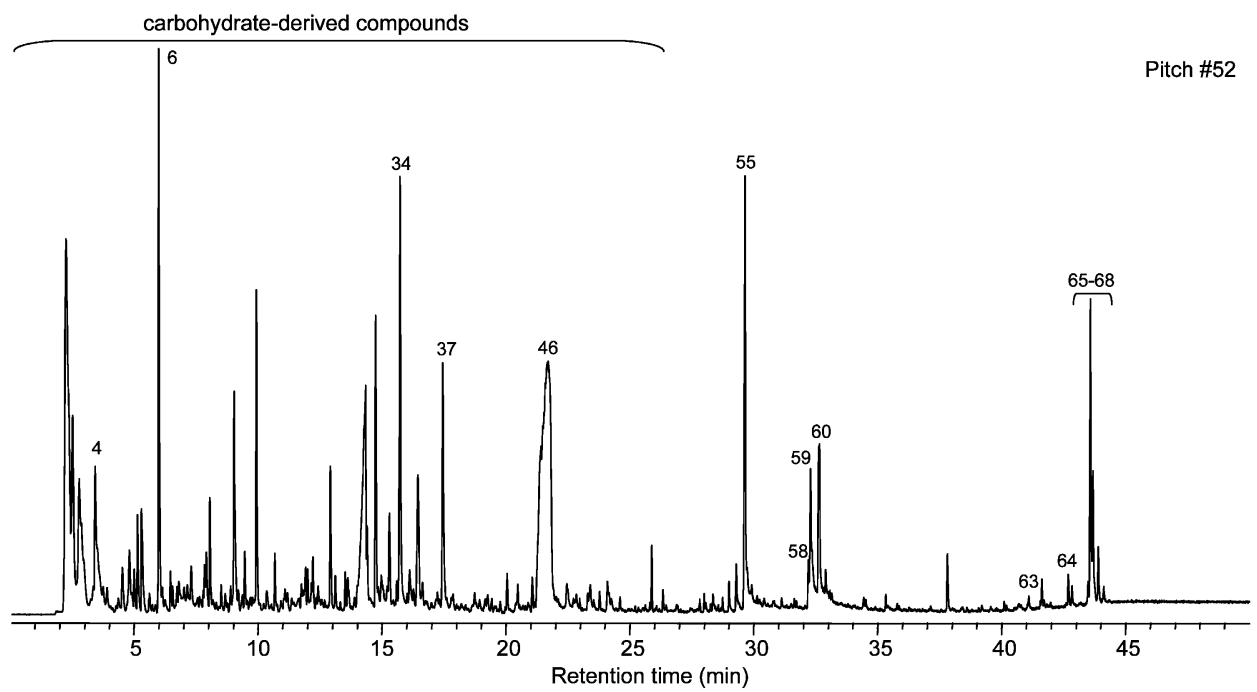

Fig. 4. Py-GC/MS of a selected impurity in TCF pulp classified as "pitch" (52). For peak identities, see Table 5.

3.2.1.1. Flexible rubbers. A total of five samples (1-5) included in this group was analyzed by Py-GC/MS. Fig. 3 shows an example of Py-GC/MS of an impurity classified as flexible rubber. The Py-GC/MS results shown in Table 6 indicated that the impurities in this category did not correspond to a unique type of rubber. Two samples ( 3 and 5) released, after pyrolysis, predominantly dipentene, a compound with a similar structure to limonene, and consisting of two isoprene units, which is characteristic of the pyrolysis of polyisoprene rubber [14]. Several other dimers, trimers and tetramers of isoprene, were also detected in the pyrograms, and so these two samples were made of polyisoprene rubber. Another two samples (2 and 4) produced upon pyrolysis of styrene, butadiene, and $\alpha$-methylstyrene, and so these pieces of rubber were made up of a copolymer of these three compounds. Finally, one of the samples (1) of this category released compounds derived from polystyrene and polyisoprene together. Besides the rubber fragments, steroid hydrocarbons occurred in the pyrograms of four of these samples but in trace amounts, indicating the contribution of pitch to these samples.

3.2.1.2. Perished rubbers. Four samples included in this group (6-9) were analyzed by Py-GC/MS. As in the previous category, the samples grouped here did not correspond to a unique type of rubber polymer. According to Py-GC/MS results (Table 6), one sample (6) was classified as being made up of polyisoprene, while the rest (7, 8 and 9) corresponded to polyisoprene/polybutadiene/polystyrene copolymers. Steroid hydrocarbons, which arise from wood extractives, were detected in all of them albeit in trace amounts, indicating the contribution of some amounts of pitch in these samples. 

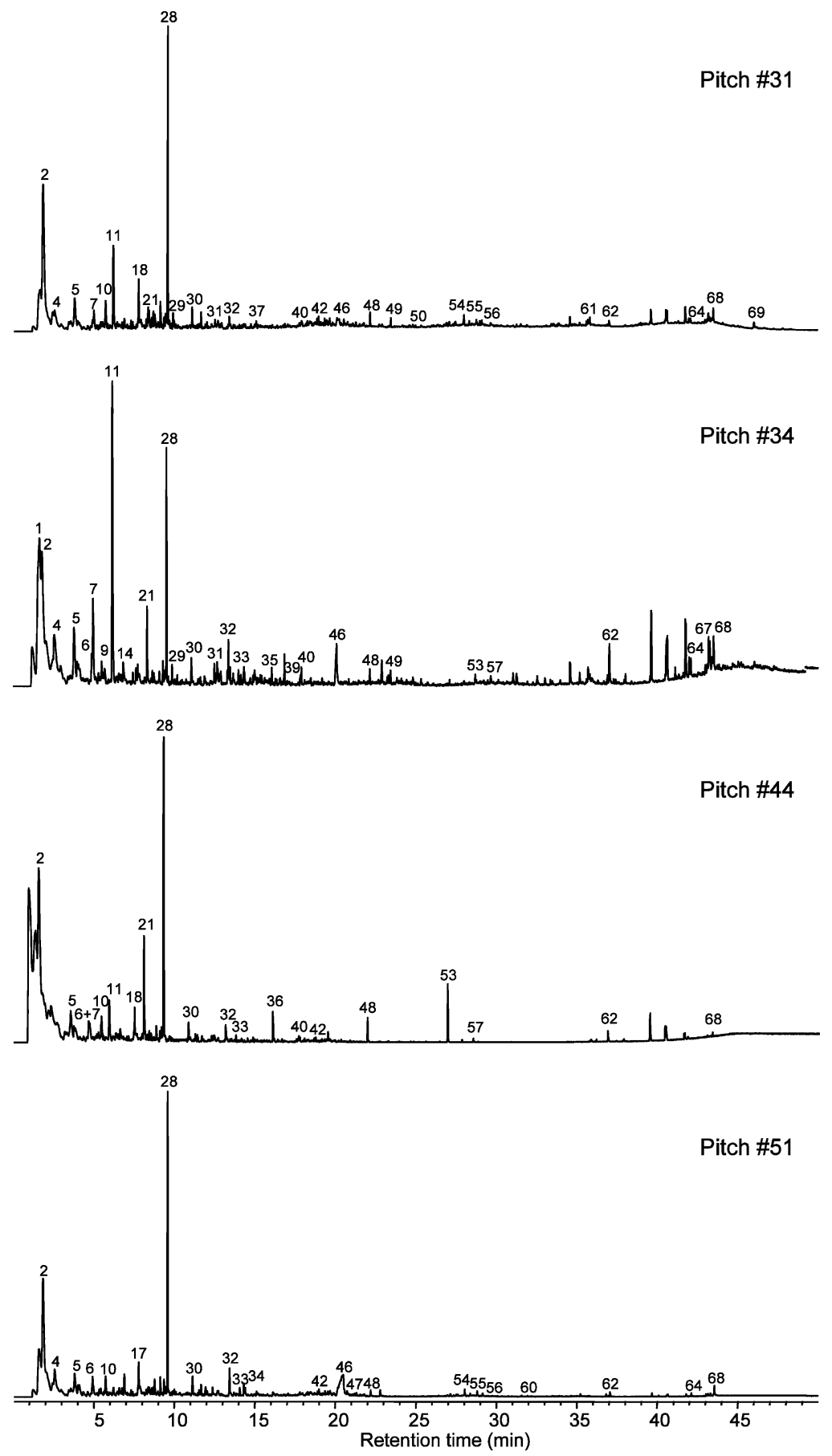

Fig. 5

Fig. 5 


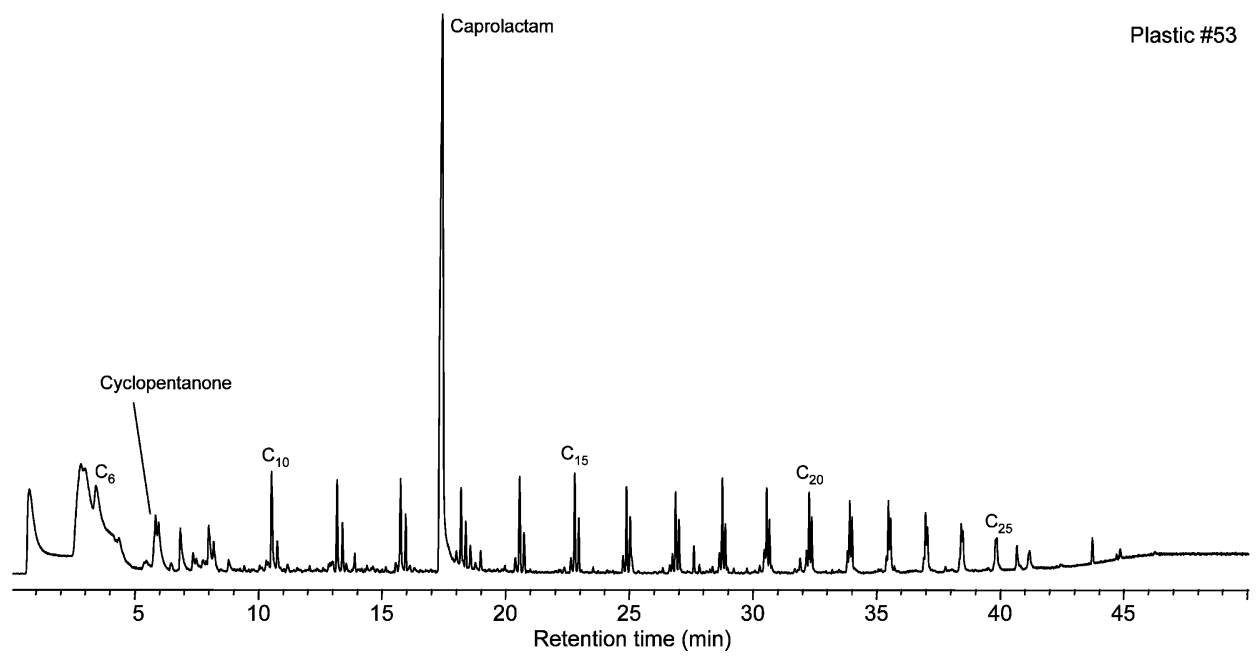

Fig. 6. Py-GC/MS of a selected impurity in TCF pulp classified as "plastic" (53).

3.2.1.3. Green rubbers. Two samples classified within this group (10 and 11) were analyzed. In this case, both samples have similar composition as revealed by Py-GC/ MS (Table 6). The main compounds produced in the pyrolysis were isoprene monomer and dimers (e.g. dipentene), trimers and tetramers of isoprene, as well as styrene and therefore corresponded to a rubber made up of a polyisoprenepolystyrene copolymer. In addition, relatively high amounts of steroid hydrocarbons arising from wood extractives were also present in the pyrogram of sample 11 indicating the contribution of pitch to this rubber sample.

3.2.1.4. Possible rubbers. Five samples classified into this group (12-16) were analyzed upon Py-GC/MS. These samples were specially difficult to separate from the fiber, and therefore a considerable number of peaks arising from the cellulose pulp appeared in the pyrograms. The pyrolysis data (Table 6) showed that all samples in this category corresponded to a polyisoprene-polystyrene copolymer. The samples in this category had been previously classified into the rubber groups upon visual checking although with a high uncertainty as being mixtures of pitch and rubber. Interestingly, no traces of steroid hydrocarbons and/or fatty acids could be detected in any of these samples upon Py-GC/MS.

\subsubsection{Py-GC/MS of impurities classified as pitch ("possible pitch" and "pitch")}

These categories include those impurities that have been unambiguously classified by mill technicians as being pitch ("pitch"), and those that are very likely to be

Fig. 5. Py-GC/MS of selected impurities in TCF pulp classified as "pitch" (31, 34, 44, 51). For peak identities, see Table 5. Note the high amounts of compounds arising from synthetic polymers in these samples. 
Table 5

List of the main compounds released from the impurities collected in TCF eucalypt kraft pulps upon PyGC/MS

\begin{tabular}{|c|c|c|}
\hline No. & Compounds & Main fragment ions $(\mathrm{m} / \mathrm{z})$ \\
\hline 1 & Butadiene & $50 / 53 / 54$ \\
\hline 2 & Isoprene & $53 / 67 / 68$ \\
\hline 3 & Methylcyclopentadiene & $77 / 79 / 80$ \\
\hline 4 & Hydroxypropanone & $43 / 74$ \\
\hline 5 & Toluene & $91 / 92$ \\
\hline 6 & Furfural & $95 / 96$ \\
\hline 7 & 4-Vinylcyclohexene & $54 / 66 / 79 / 93 / 108$ \\
\hline 8 & Furfuryl alcohol & $53 / 69 / 81 / 97 / 98$ \\
\hline 9 & Ethylbenzene & $91 / 106$ \\
\hline 10 & Xylene & $91 / 106$ \\
\hline 11 & Styrene & $78 / 103 / 104$ \\
\hline 12 & (5H) Furan-2-one & $55 / 84$ \\
\hline 13 & Isoprene dimer & $105 / 121 / 136$ \\
\hline 14 & Hydroxycyclopentenone & $42 / 55 / 69 / 98$ \\
\hline 15 & C3-alkylbenzene & $91 / 120$ \\
\hline 16 & C3:1-alkenylbenzene & $91 / 115 / 117 / 118$ \\
\hline 17 & Isoprene dimer & $107 / 121 / 136$ \\
\hline 18 & Isoprene dimer & $107 / 121 / 136$ \\
\hline 19 & Methylfurfural & $53 / 81 / 109 / 110$ \\
\hline 20 & C3-alkylbenzene & $105 / 120$ \\
\hline 21 & $\alpha$-Methylstyrene & 78/91/103/117/118 \\
\hline 22 & Methylstyrene & $91 / 103 / 117 / 118$ \\
\hline 23 & Methylstyrene & $91 / 103 / 117 / 118$ \\
\hline 24 & Isoprene dimer & $105 / 121 / 136$ \\
\hline 25 & 2-Hydroxy-3-methyl-2-cyclopenten-1-one & $55 / 69 / 83 / 97 / 112$ \\
\hline 26 & C3-alkylbenzene & $105 / 120$ \\
\hline 27 & Methylisopropylbenzene & $91 / 105 / 119 / 134$ \\
\hline 28 & Isoprene dimer (Dipentene) & $107 / 121 / 136$ \\
\hline 29 & Indene & $115 / 116$ \\
\hline 30 & Methylisopropenylbenzene & $91 / 117 / 132$ \\
\hline 31 & Methylindene & $115 / 129 / 130$ \\
\hline 32 & Unknown & $57 / 58 / 69 / 70 / 82 / 85 / 96 / 116 / 128$ \\
\hline 33 & Dianhydro- $\alpha$-D-glucopyranose & $57 / 69 / 85 / 98 / 114 / 144$ \\
\hline 34 & Hydroxymethylfurfural & $69 / 97 / 126$ \\
\hline 35 & C2-indene & $115 / 129 / 130$ \\
\hline 36 & Phthalic acid & $76 / 104 / 148$ \\
\hline 37 & C2-indene & $115 / 129 / 144$ \\
\hline 38 & C3-indene & $115 / 128 / 143 / 158$ \\
\hline 39 & $\alpha$-Methylstyrene-butadiene dimer & $117 / 118 / 157 / 172$ \\
\hline 40 & 2-Vinylnaphthalene & $76 / 128 / 154$ \\
\hline 41 & Isoprene trimer & $119 / 161 / 175 / 189 / 204$ \\
\hline 42 & Isoprene trimer & $121 / 161 / 175 / 189 / 204$ \\
\hline 43 & Isoprene trimer & $119 / 161 / 175 / 189 / 204$ \\
\hline 44 & Isoprene trimer & $119 / 161 / 189 / 189 / 204$ \\
\hline 45 & Isoprene trimer & $119 / 161 / 175 / 189 / 204$ \\
\hline 46 & Levoglucosan & $60 / 73 / 98 / 144$ \\
\hline 47 & Isoprene trimer & $119 / 161 / 175 / 189 / 204$ \\
\hline 48 & Ethylphthalate & $149 / 177 / 222$ \\
\hline
\end{tabular}


Table 5 (Continued)

\begin{tabular}{|c|c|c|}
\hline No. & Compounds & Main fragment ions $(\mathrm{m} / \mathrm{z})$ \\
\hline 49 & 1,3-Diphenylpropane & $91 / 105 / 196$ \\
\hline 50 & 1,3-Diphenylpropene & $91 / 115 / 179 / 193 / 194$ \\
\hline 51 & 1,4-Diphenylbutane & $91 / 92 / 104 / 117 / 210$ \\
\hline 52 & Isoprene tetramer & $121 / 175 / 229 / 272$ \\
\hline 53 & Isobutylphthalate & $149 / 167 / 223$ \\
\hline 54 & Isoprene tetramer & $91 / 107 / 121 / 175 / 229 / 272$ \\
\hline 55 & $n$-Hexadecanoic acid & $60 / 73 / 129 / 256$ \\
\hline 56 & Isoprene tetramer & $93 / 107 / 119 / 175 / 229 / 272$ \\
\hline 57 & Butylphthalate & $149 / 205 / 223$ \\
\hline 58 & 9,12 -Octadecadienoic acid & $55 / 67 / 81 / 95 / 280$ \\
\hline 59 & 9-Octadecenoic acid & $55 / 67 / 81 / 97 / 264 / 282$ \\
\hline 60 & $n$-Octadecanoic acid & $57 / 60 / 73 / 129 / 284$ \\
\hline 61 & Styrene trimer & $91 / 117 / 194 / 297 / 312$ \\
\hline 62 & Isooctylphthalate & $149 / 167 / 279$ \\
\hline 63 & Squalene & $69 / 81 / 137 / 410$ \\
\hline 64 & Steroid hydrocarbon $\mathrm{C}_{29: 2}$ & $145 / 213 / 255 / 275 / 381 / 396$ \\
\hline 65 & Steroid hydrocarbon $\mathrm{C}_{29 \cdot 1}$ & $147 / 215 / 257 / 344 / 383 / 398$ \\
\hline 66 & Steroid hydrocarbon $\mathrm{C}_{29: 2}$ & $145 / 213 / 255 / 342 / 381 / 396$ \\
\hline 67 & Steroid hydrocarbon $\mathrm{C}_{29: 3}$ & $135 / 143 / 394$ \\
\hline 68 & Steroid hydrocarbon $\mathrm{C}_{29: 2}$ & $145 / 213 / 255 / 275 / 288 / 381 / 396$ \\
\hline
\end{tabular}

composed of wood extractives but with some uncertainty as being mixed with rubber ("possible pitch"). However, as shown below, Py-GC/MS results indicate that the classification of the impurities in these two categories have been erroneously assigned by visual checking. Due to the high importance in the mill to distinguish between pitch and rubber impurities in the pulp, a large set of samples (28 samples) included among the "pitch" category by visual checking, were collected and analyzed in detail.

3.2.2.1. Possible pitch. Although eight samples were classified as being "possible pitch" (17-24), characteristic compounds of wood extractives (pitch), such as steroid hydrocarbons and/or fatty acids, could only be detected by Py-GC/MS in two of those samples (18 and 24), although in trace amounts (Table 7). All the samples released predominantly dipentene (dimer of isoprene) together with isoprene and several other dimers, trimers and tetramers of isoprene. Therefore, according to the results, we could conclude that all these impurities in this category were made of polyisoprene rubber.

3.2.2.2. Pitch. Twenty-eight samples (25-52), which were unambiguously classified by mill technicians as being pitch by visual checking of their physical aspect, were selected for this study. However, detailed analysis by Py-GC/MS (see Table 8) showed that only sample 52 released, besides compounds arising from the cellulose fiber, high amounts of compounds characteristics of the presence of wood extractives (pitch), namely fatty acids and steroid hydrocarbons (Fig. 4). Characteristic 
Table 6

Results obtained in the analysis by Py-GC/MS of the impurities in TCF pulp, previously classified by mill technicians as "flexible rubbers", "perished rubbers", "green rubbers" and "possible rubbers"

\begin{tabular}{|c|c|c|c|c|c|c|c|c|c|c|c|c|c|c|c|c|}
\hline & \multicolumn{5}{|c|}{ Flexible rubbers } & \multicolumn{4}{|c|}{ Perished rubbers } & \multicolumn{2}{|c|}{ Green rubbers } & \multicolumn{5}{|c|}{ Possible rubbers } \\
\hline & 1 & 2 & 3 & 4 & 5 & 6 & 7 & 8 & 9 & 10 & 11 & 12 & 13 & 14 & 15 & 16 \\
\hline Sterol hydrocarbons & tr. & $\operatorname{tr}$ & $\operatorname{tr}$ & $\operatorname{tr}$ & n.d. & $\operatorname{tr}$ & tr. & $\operatorname{tr}$ & $\operatorname{tr}$ & $\operatorname{tr}$ & 1.1 & n.d. & n.d. & n.d. & n.d. & n.d. \\
\hline Fatty acids & n.d. & n.d. & n.d. & n.d. & n.d. & n.d. & n.d. & n.d. & n.d. & n.d. & n.d. & n.d. & n.d. & n.d. & n.d. & n.d. \\
\hline Isoprene & 25 & 3 & 30 & n.d. & 30 & 28 & 22 & 25 & 28 & 25 & 23 & 22 & 25 & 28 & 22 & 19 \\
\hline Isoprene dimers & 35 & 5 & 41 & 2 & 46 & 48 & 35 & 41 & 44 & 34 & 35 & 12 & 29 & 36 & 14 & 20 \\
\hline Isoprene trimers and tetramers & 4 & n.d. & 2 & n.d. & 2 & 6 & 3 & 3 & 5 & 2 & 1 & 1 & 1 & 1 & n.d. & n.d. \\
\hline Styrene & 12 & 35 & n.d. & 38 & 5 & 1 & 7 & 10 & 6 & 9 & 9 & 2 & 4 & 3 & 9 & 4 \\
\hline$\alpha$-Methylstyrene & 3 & 3 & n.d. & 3 & 2 & n.d. & 6 & 2 & 2 & 2 & 2 & n.d. & $\operatorname{tr}$ & 2 & n.d. & n.d. \\
\hline Methylstyrene & n.d. & n.d. & n.d. & 1 & 1 & n.d. & n.d. & n.d. & n.d. & n.d. & n.d. & n.d. & n.d. & n.d. & n.d. & n.d. \\
\hline 4-Vinylcyclohexene & 4 & 10 & n.d. & 10 & 2 & n.d. & 4 & 3 & 2 & 4 & 5 & n.d. & n.d. & 3 & n.d. & n.d. \\
\hline Carbohydrate compounds & 3 & 3 & 5 & 2 & 2 & 7 & 3 & 2 & 3 & 3 & 3 & 29 & 18 & 7 & 21 & 29 \\
\hline Phthalates & 1 & 2 & 1 & 3 & 2 & 3 & 2 & 1 & 3 & 1 & 2 & 12 & 1 & tr. & 6 & $\operatorname{tr}$ \\
\hline Total diagnostic compounds ${ }^{\mathrm{a}}$ & 87 & 61 & 79 & 59 & 92 & 93 & 82 & 87 & 93 & 80 & 80 & 78 & 78 & 80 & 72 & 72 \\
\hline
\end{tabular}

The results are expressed as percentage of the total area of the pyrogram. n.d., not detected; tr., detected in trace amounts

a The rest corresponded to non-diagnostic compounds such as alkylbenzenes and alkylindenes. 
Table 7

Results obtained in the analysis by Py-GC/MS of the impurities in TCF pulp, previously classified by mill technicians as "possible pitch"

\begin{tabular}{|c|c|c|c|c|c|c|c|c|}
\hline & \multicolumn{8}{|c|}{ Possible pitch } \\
\hline & 17 & 18 & 19 & 20 & 21 & 22 & 23 & 24 \\
\hline Sterol hydrocarbons & n.d. & n.d. & n.d. & n.d. & n.d. & n.d. & n.d. & $\operatorname{tr}$. \\
\hline Fatty acids & n.d. & $\operatorname{tr}$. & n.d. & n.d. & n.d. & n.d. & n.d. & $\operatorname{tr}$. \\
\hline Isoprene & 25 & 12 & 27 & 23 & 18 & 29 & 25 & 26 \\
\hline Isoprene dimers & 31 & 7 & 35 & 27 & 18 & 39 & 32 & 36 \\
\hline Isoprene trimers and tetramers & 1 & n.d. & 1 & 1 & n.d. & 1 & 1 & 1 \\
\hline Styrene & 3 & $\operatorname{tr}$ & 2 & 5 & $\operatorname{tr}$ & 2 & n.d. & n.d. \\
\hline$\alpha$-Methylstyrene & tr. & n.d. & $\operatorname{tr}$. & $\operatorname{tr}$. & n.d. & $\operatorname{tr}$. & n.d. & n.d. \\
\hline Methylstyrene & n.d. & n.d. & n.d. & n.d. & n.d. & n.d. & n.d. & n.d. \\
\hline 4-Vinylcyclohexene & n.d. & n.d. & n.d. & n.d. & n.d. & n.d. & n.d. & n.d. \\
\hline Carbohydrate compounds & 20 & 44 & 16 & 17 & 34 & 12 & 20 & 17 \\
\hline Phthalates & 1 & 1 & $\operatorname{tr}$ & 3 & 1 & 3 & 2 & 2 \\
\hline Total diagnostic compounds ${ }^{\mathrm{a}}$ & 81 & 64 & 81 & 76 & 71 & 86 & 80 & 82 \\
\hline
\end{tabular}

The results are expressed as the percentage of the total area of the pyrogram. n.d., not detected; tr., detected in trace amounts.

a The rest corresponded to non-diagnostic compounds such as alkylbenzenes and alkylindenes.

compounds of the presence of pitch were also observed in appreciable amounts in six other samples $(31,33,34,38,48$ and 51$)$ while in some others were present in very minor or trace amounts. No traces of wood extractives were released from the rest of the samples upon Py-GC/MS, indicating the absence of pitch in these samples. In contrast, all samples in this category, except sample 52, released high amount of compounds arising from synthetic polymers. Fig. 5 shows some examples of impurities classified as pitch but that released compounds from synthetic polymers. Most samples in this category released predominant compounds arising from polyisoprene rubber, such as isoprene, dipentene and other dimers, trimers and tetramers of isoprene. Compounds arising from the pyrolysis of polystyrene were also detected in the pyrograms although only in seven samples $(31,34,38,39,40,41$ and 44) the amounts of styrene, methylstyrene and $\alpha$-methylstyrene were significant. Finally, one of the samples (34) released high amounts of butadiene (accounting for $13.4 \%$ of the released compounds) pointing out to the presence of polybutadiene.

\subsubsection{Py-GC/MS of impurities classified as "plastics"}

Four samples (53-56) belonging to the plastics group were analyzed by Py-GC/ MS. The results showed that all the samples in this category were correctly classified as plastics upon visual checking. No steroid hydrocarbons and/or fatty acids were found in any of them upon Py-GC/MS indicating the absence of pitch. In one sample (53), two characteristic components from polyamide fiber (nylon-6), caprolactam $\left(\mathrm{C}_{6} \mathrm{H}_{11} \mathrm{NO}\right)$ and cyclopentanone $\left(\mathrm{C}_{5} \mathrm{H}_{8} \mathrm{O}\right)$ [15,16] were detected (Fig. 6). The caprolactam proportion was $45 \%$. Another $43 \%$ of this sample corresponded to a series of alkenes and alkanes, which occurs after the breaking up of the polyethylene 
Table 8

Results obtained in the analysis by Py-GC/MS of the impurities in TCF pulp, previously classified by mill technicians as "pitch"

\begin{tabular}{|c|c|c|c|c|c|c|c|c|c|c|c|c|c|c|c|c|c|c|c|c|c|c|c|c|c|c|c|c|}
\hline & \multicolumn{28}{|c|}{ Pitch } \\
\hline & 25 & 26 & 27 & 28 & 29 & 30 & 31 & 32 & 33 & $34^{\mathrm{a}}$ & 35 & 36 & 37 & 38 & 39 & 40 & 41 & 42 & 43 & 44 & 45 & 46 & 47 & 48 & 49 & 50 & 51 & 52 \\
\hline $\begin{array}{l}\text { Sterol hydrocar- } \\
\text { bons }\end{array}$ & n.d. & n.d. & n.d. & n.d. & n.d. & n.d. & 2 & n.d. & 2 & 4 & $\operatorname{tr}$ & $\operatorname{tr}$. & $\operatorname{tr}$ & 4 & $\operatorname{tr}$ & $\operatorname{tr}$ & tr. & tr. & n.d. & $\operatorname{tr}$ & n.d. & tr. & tr. & 1 & $\operatorname{tr}$ & $\operatorname{tr}$ & 2 & 9 \\
\hline Fatty acids & n.d. & n.d. & n.d. & n.d. & n.d. & tr. & tr. & tr. & tr. & n.d. & n.d. & $\operatorname{tr}$ & n.d. & n.d. & n.d. & n.d. & n.d. & n.d. & tr. & n.d. & n.d. & n.d. & $\operatorname{tr}$ & tr. & $\operatorname{tr}$ & $\operatorname{tr}$ & $\operatorname{tr}$ & 10 \\
\hline Isoprene & 39 & 34 & 36 & 53 & 38 & 1 & 27 & 26 & 29 & 12 & 27 & 25 & 33 & 21 & 30 & 27 & 32 & 38 & 26 & 23 & 22 & 29 & 20 & 26 & 31 & 30 & 24 & n.d. \\
\hline Isoprene dimers & 24 & 31 & 25 & 18 & 19 & 10 & 29 & 20 & 25 & 7 & 32 & 9 & 23 & 27 & 23 & 20 & 24 & 18 & 14 & 21 & 14 & 33 & 13 & 32 & 30 & 25 & 27 & n.d. \\
\hline $\begin{array}{l}\text { Isoprene trimers } \\
\text { and tetramers }\end{array}$ & 1 & 3 & 1 & 1 & 1 & n.d. & 2 & 1 & 1 & n.d. & $\operatorname{tr}$ & n.d. & 1 & n.d. & 1 & n.d. & n.d. & n.d. & 1 & 1 & n.d. & tr. & 1 & tr. & $\operatorname{tr}$ & n.d. & tr. & n.d. \\
\hline Styrene & 4 & 4 & 6 & 5 & 2 & 4 & 9 & tr. & 2 & 15 & tr. & 6 & 6 & 9 & 4 & 4 & 5 & 5 & 4 & 5 & 4 & n.d. & 3 & 2 & 2 & 3 & n.d. & n.d. \\
\hline Methylstyrene & n.d. & n.d. & n.d. & n.d. & n.d. & n.d. & 2 & tr. & $\operatorname{tr}$ & tr. & 1 & tr. & 1 & 1 & 1 & n.d. & 1 & 1 & tr. & 1 & 1 & 1 & 1 & 1 & 1 & 1 & n.d. & n.d. \\
\hline$\alpha$-Methylstyrene & tr. & tr. & tr. & 1 & $\operatorname{tr}$ & n.d. & 2 & n.d. & $\operatorname{tr}$ & 3 & n.d. & $\operatorname{tr}$ & 1 & 1 & 7 & 5 & 1 & tr. & 1 & 7 & tr. & n.d. & tr. & tr. & $\operatorname{tr}$ & 1 & n.d. & n.d. \\
\hline 4-Vinylcyclohexene & $\operatorname{tr}$. & tr. & tr. & 1 & tr. & tr. & 2 & n.d. & n.d. & 5 & n.d. & n.d. & 2 & 4 & 2 & $\operatorname{tr}$ & tr. & tr. & tr. & 2 & tr. & n.d. & tr. & n.d. & n.d. & $\operatorname{tr}$ & n.d. & n.d. \\
\hline $\begin{array}{l}\text { Carbohydrate } \\
\text { compounds }\end{array}$ & 12 & 10 & 11 & tr. & 16 & 38 & 6 & 19 & 12 & 11 & 12 & 25 & 11 & 8 & 6 & 23 & 14 & 19 & 16 & 10 & 22 & 8 & 29 & 15 & 16 & 21 & 28 & 79 \\
\hline Phthalates & 2 & 1 & 2 & 2 & 2 & 1 & 1 & 1 & 1 & 2 & 1 & 6 & 1 & 8 & 2 & 2 & 5 & 5 & 11 & 8 & 11 & 10 & 6 & 6 & tr. & 1 & tr. & 1 \\
\hline $\begin{array}{l}\text { Total diagnostic } \\
\text { compounds }{ }^{\mathrm{b}}\end{array}$ & 82 & 83 & 81 & 81 & 78 & 54 & 82 & 67 & 72 & 73 & 73 & 71 & 79 & 83 & 76 & 81 & 82 & 86 & 73 & 78 & 74 & 81 & 73 & 83 & 80 & 82 & 81 & 99 \\
\hline
\end{tabular}

The results are expressed as the percentage of the total area of the pyrogram. n.d., not detected; tr., detected in trace amounts.

a Butadiene was also identified representing $14 \%$ of the total compounds identified.

b The rest corresponded to non-diagnostic compounds such as alkylbenzenes and alkylindenes. 
at high temperatures [17]. So, the speck was possibly a mixture of polyamide and polyethylene. The same set of alkenes and alkanes, but in higher amounts $(70 \%)$, was identified in the rest of the samples indicating their polyethylene nature.

Taking into account all these results, it is obvious that the differentiation made in the mill by visual checking is highly inaccurate, except for the impurities classified as plastics. Apart from the presence or absence of pitch in some samples, all impurities analyzed, even those unambiguously classified as pitch (except 52), contained small fragments of synthetic rubbers. This suggests that small rubber pieces arising from machine breakage are a major source of pulp contamination in the mill. A rapid characterization of the impurities and the determination of their source are important in order to undertake appropriate measures. In this sense, the pyrograms of different reference rubbers collected from the machinery can be used as fingerprints to trace back the source of contamination. Therefore, comparing PyGC/MS data of the impurities with those of the reference materials, it was possible to form five different groups: (A) impurities with important amount of polyisoprene similar to reference rubber R17; (B) impurities with important amounts of polyisoprene and polystyrene and similar to reference rubber R16; (C) impurities with important amounts of polyisoprene and poly- $\alpha$-methylstyrene, similar to R04 and R10 reference rubbers; (D) impurities with important amounts of polystyrene similar to R09 reference rubber and (E) impurities with important amounts of polyisoprene, polystyrene and polybutadiene, similar to R7, R8 and R18 reference rubbers.

\section{Conclusions}

Py-GC/MS has proven to be an effective analytical technique to characterize small impurities in pulp, without sample treatment, and to distinguish between different synthetic polymers. Taking into account the results obtained in this study, almost all impurities analyzed in this work and collected from chlorine-free pulps had fragments of synthetic rubbers arising from machine breakage from different parts of the mill. In addition, most of them also had compounds that come from wood extractives (pitch) in its composition. However, inherent limitations of this technique have made it impossible to quantify the proportion of pitch and rubbers in mixed samples. The identification of the composition of the impurities in pulp will help to trace them back to their source, and define strategies for their control.

\section{Acknowledgements}

This work has been supported by the European Commission (project QLK5-991357). A. Gutiérrez is thankful for a "Ramón y Cajal" contract of the Spanish MCYT. 


\section{References}

[1] E.L. Back, L.H. Allen (Eds.), Pitch Control, Wood Resin and Deresination, TAPPI Press, Atlanta, GA, 2000.

[2] W.E. Hillis, M. Suminoto, in: J.W. Rowe (Ed.), Natural Products of Woody Plants, Springer, Berlin, 1989, p. 880 .

[3] J.C. del Río, A. Gutiérrez, F.J. González-Vila, J. Chromatogr. A 830 (1999) 227.

[4] J.C. del Río, A. Gutiérrez, F.J. González-Vila, F. Martín, J. Anal. Appl. Pyrol. 49 (1999) 165.

[5] T.D. Crockett, A.A. Webb, L.G. Borchardt, D.B. Easty, J. Chromatogr. A 407 (1987) 330.

[6] N. Dunlop-Jones, L.H. Allen, Tappi J. 71 (1988) 109.

[7] B.B. Sitholé, L.H. Allen, J. Pulp Pap. Can. 20 (1994) 168.

[8] H.-L. Hardell, J. Anal. Appl. Pyrol. 27 (1993) 73.

[9] A. Gutiérrez, J.C. del Río, F.J. González-Vila, F. Martín, Holzforschung 53 (1999) 481.

[10] J.C. del Río, A. Gutiérrez, F.J. González-Vila, F. Martín, J. Romero, J. Chromatogr. A 823 (1998) 457.

[11] J.C. del Río, J. Romero, A. Gutiérrez, J. Chromatogr. A 874 (2000) 235.

[12] A. Gutiérrez, J. Romero, J.C. del Río, Holzforschung 55 (2001) 206.

[13] A. Gutiérrez, J. Romero, J.C. del Río, Chemosphere 44 (2001) 1237.

[14] S.G. Roussis, J.W. Fedora, Rapid Commun. Mass Spectrom. 10 (1996) 82.

[15] B.G. Achammer, F.W. Renhart, G.M. Kline, J. Res. Natl. Bur. Stand. 46 (1951) 391.

[16] H. Bockhorn, S. Donner, M. Gernsbeck, A. Hornung, U. Hornung, J. Anal. Appl. Pyrol. 58/59 (2001) 79.

[17] R.P. Lattimer, J. Anal. Appl. Pyrol. 31 (1995) 203. 